\title{
A revolução verde e a modernização agrícola na mesorregião noroeste do Rio Grande do Sul - 1960/1970
}

\author{
Clovis Tadeu Alves" \\ João Carlos Tedesco***
}

\begin{abstract}
Resumo
Este artigo reconstitui o início da especialização produtiva agrícola na mesorregião noroeste do Rio Grande do Sul, com a introdução do pacote tecnológico da revolução verde, com ênfase nas transformações ocorridas na agricultura nessa região. O estudo justifica-se pela relevância histórica do tema para o território em questão, no qual a agricultura foi a primeira e principal forma de atividade econômica, e também devido às transformações ocorridas, que modificaram todo o sistema econômico, social e agrário. Este trabalho pretende demonstrar como ocorreu a formação e a consolidação do programa de modernização agrícola, representadas pela revolução verde, na mesorregião noroeste, e o começo da disseminação do modelo para outras regiões do país, analisando o período que engloba as décadas de 1960 e 1970.
\end{abstract}

Palavras-chave: Revoluçao verde. Modernização agrícola. Mesorregião noroeste.

" Bacharel em Ciências Econômicas. Mestre em História. Professor da Universidade de Passo Fundo. E-mail: clovis21@ibest.com.br

** Doutor em Ciências Sociais. Professor do Programa de Pós-Graduação em História da Universidade de Passo Fundo. E-mail: jctedesco@upf.br

http://dx.doi.org/10.5335/rtee.v21i45.6187

Submissão: 15/09/2015. Aceite: 25/02/2016. 


\section{Introdução}

A revolução verde no Brasil modernizou a agricultura e, com isso, acabou com a dependência histórica da produção cafeeira na agricultura brasileira. Essas pretensões, além de ambiciosas, tinham de conciliar diversos interesses estratégicos, econômicos e geopolíticos para resultar em êxito. Essa conciliação era só uma face dos problemas que a revolução verde teria de enfrentar para alcançar seus propósitos no Brasil, a outra eram as limitações climáticas e geográficas do território brasileiro, que formavam uma verdadeira barreira, que, talvez, nem mesmo a introdução de máquinas, fertilizantes e sementes híbridas revolucionariam a agricultura brasileira. Denota-se, assim, que a região sul do Brasil era o lugar que reunia as condições climáticas, sociais e econômicas ideais para a implantação exitosa da revolução verde nas décadas de 1960 e 1970. A tecnologia da revolução verde não estava pronta para ser implantada em todo o território brasileiro, pois tinha um perfil para a agricultura de clima temperado e havia problemas para adaptá-la para o clima tropical brasileiro.

A criação do moderno agronegócio brasileiro, principalmente no que concerne às atividades relacionadas à produção de cereais e oleaginosas, deve grande parte do seu sucesso a uma região produtiva do Rio Grande do Sul, a mesorregião noroeste, na qual, na segunda metade do século XX, iniciou-se um processo de modernização agrícola, que a transformou em um ponto de convergência da agricultura brasileira. A revolução verde introduziu a tecnologia na agricultura mesorregional, auxiliando na resolução de uma complicada equação para o país, destravando o fornecimento de matéria-prima para a indústria em expansão e fornecendo gêneros alimentícios para um país cada vez mais urbano.

Os autores Brum (1983), Rückert ${ }^{1}$ (2003) e Albuquerque e Silva ${ }^{2}$ (2008) são unânimes em afirmar que a modernização da agricultura brasileira teve início no Planalto Médio gaúcho com o trigo, ainda na década de 1940. Mas, foi nas décadas de 1960 e 1970, com a revolução verde, que o modelo ganhou escala, espalhando-se para outras regiões do país. Observando as opiniões desses autores, e no intuito de melhor especificar a região estudada, definiu-se por utilizar a nomenclatura mesorregião noroeste do Rio Grande do Sul. ${ }^{3}$ Foi essa região que obteve maior êxito nesse empreendimento. Esse fato, aliado a políticas agrícolas e econômicas, transformou todo o sistema agrícola local.

A dinâmica dos acontecimentos nessa região do país processou-se com a gradual introdução da tecnologia agrícola no início na década de 1930, especialmente no estado do Rio Grande do Sul. Assim, pode-se dividir todo o processo de implantação 
do modelo no Estado em dois períodos distintos: o processo de implantação, com a intervenção governamental na cultura do trigo, que compreende as décadas de 1930, 1940 e 1950, e o processo de difusão tecnológica e de consolidação da revolução verde em si, com a cultura da soja, compreendendo as décadas de 1960 e 1970.

O tema central deste artigo é o processo de transformação ocorrido na agricultura da mesorregião noroeste com a consolidação da revolução verde. Tais transformações, nas décadas de 1960 e 1970, afetaram as principais estruturas agrícolas mesorregionais, determinando a transformação das cooperativas em multicooperativas e o desenvolvimento de um polo de máquinas agrícolas, consolidando um processo de industrialização da produção agrícola, que se intensifica com a criação da Embrapa (novas tecnologias) e com os incentivos governamentais (crédito subsidiado). A nova realidade agrícola aumentou as trocas entre os setores, dando uma nova dinâmica econômica para a agricultura, integrando-a à economia de mercado. Os elementos fundamentais da revolução verde nesse processo histórico são o desenvolvimento do complexo agroindustrial e as consequências para os produtores e a sociedade mesorregional.

\section{A revolução verde na mesorregião noroeste do Rio Grande do Sul}

Nas décadas de 1950 e 1960, as grandes agências de desenvolvimento tentaram fazer o desenvolvimento econômico ocidental mais acessível, capaz de levar o capitalismo para o interior dos continentes. Iniciou-se com a propagação de novas e modernas práticas agrícolas "entre os grupos camponeses com que trabalharam por meio do aperfeiçoamento dos pacotes tecnológicos que chegavam a eles por parte de agrônomos e programas internacionais de desenvolvimento" (FOSTER, 1964, apud LITTLE, 2002, p. 37).

O movimento das agências e instituições filantrópicas privadas para o desenvolvimento da agricultura foi posteriormente denominado revolução verde, que se apresenta como uma resposta tecnológica para a escassez mundial de alimentos ou para as dificuldades em se produzir alimentos para uma população sempre crescente. Nessa perspectiva, a produção em larga escala com uso de tecnologia aplicada à agricultura foi a solução encontrada, ou escolhida, para, dentro de certa perspectiva, combater a fome no mundo.

Nesse sentido, segundo Brum (1983, p. 55), a revolução verde era uma experiência produtiva que pretendia, por meio da mudança tecnológica ou da técnica 
utilizada, transformar a agricultura em um ambiente mais controlado, tornando o trabalho do produtor ou do trabalhador rural uma atividade mais mecânica e 'fordilizada', dentro da lógica de expansão do capitalismo no espaço rural. Assim, o uso de sementes melhoradas - híbridas - e de máquinas e técnicas consideradas modernas garantiriam melhores resultados do que a tecnologia e o conhecimento então existentes, considerados primitivos e atrasados.

Segundo Alves, a revolução verde foi um programa modernizante que preconizava que a agricultura não podia mais ser uma relação social e tradicional do agricultor com a terra. Seria, "sim, uma relação complexa entre o agricultor, o mercado financeiro (bancos), a indústria metal-mecânica (máquinas e equipamentos agrícolas), a indústria química (fertilizantes e defensivos agrícolas) e a indústria de pesquisa de tecnologia agrícola" (2013, p. 26-27).

Uma das características mais marcantes, mas pouco lembrada, era o viés visando à agricultura para clima temperado do pacote tecnológico da revolução verde. Por que isso era tão importante? Porque a tecnologia da revolução verde foi desenvolvida para atender aos condicionantes naturais da agricultura praticada nos Estados Unidos, uma agricultura caracterizada pelo predomínio de variedades de clima temperado, que não se adaptava muito bem ao clima tropical brasileiro, embora conseguisse prevalecer na região sul do Brasil, região de clima semelhante ao de algumas regiões norte-americanas.

O movimento das grandes agências de desenvolvimento internacionais e esse viés tecnológico da revolução verde refletiram-se na agricultura brasileira, principalmente em uma região do estado do Rio Grande do Sul, que passou a ser a principal fronteira agrícola brasileira do século XX. Foi na mesorregião noroeste que o pacote tecnológico encontrou os condicionantes para a sua reprodução e futura expansão na agricultura do país. A revolução verde foi mais incisiva nessa mesorregião e introduziu a tecnologia no setor agrícola, auxiliando na resolução de uma complicada equação do país e destravando o fornecimento de matéria-prima para a indústria em expansão, fornecendo gêneros alimentícios para um país cada vez mais urbano.

A mesorregião noroeste sul-rio-grandense, em destaque na Figura 1, compreende as regiões do Planalto Médio, do Alto Uruguai, de parte da Centro-Serra, do Médio Alto Uruguai, das Missões e do Noroeste Colonial. É formada pelas microrregiões de Carazinho, Cerro Largo, Cruz Alta, Erechim, Frederico Westphalen, Ijuí, Passo Fundo, Sananduva, Santa Rosa, Santo Ângelo, Soledade e Três Passos. Segundo dados do Instituto Brasileiro de Geografia e Estatística (2010), a mesorregião noroeste abrange uma área de $64.942,00 \mathrm{~km}^{2}$, representando $24,16 \%$ 
do território do estado, com uma população de 1.946 .510 pessoas, que representam $18,20 \%$ do contingente populacional do Rio Grande do Sul. Está dividida em 223 municípios, com um PIB de $\mathrm{R} \$ 20.634 .904 .250,00$, resultando em um PIB per capita, em média, de $\mathrm{R} \$ 10.161,91$. Constitui-se na principal região produtiva do estado e, a partir da década de 1950, em uma das principais regiões de produção agrícola do país.

Figura 1 - Mesorregião noroeste do Rio Grande do Sul

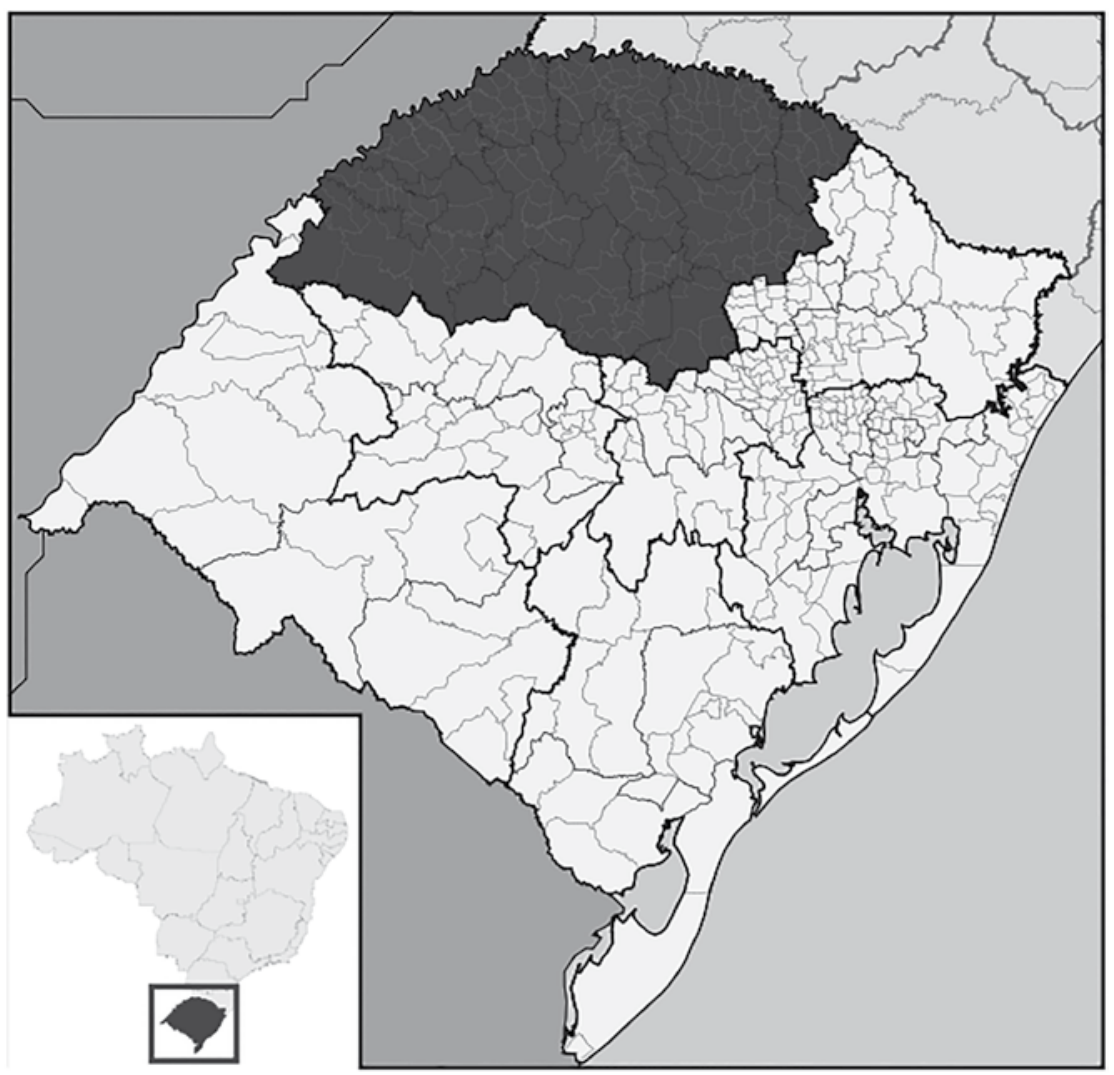

Fonte: Wikipédia. Disponível em: <http://pt.wikipedia.org/wiki/Ficheiro:RioGrandedoSul_Meso_NoroesteRioGrandense.svg>.

A mesorregião noroeste congrega, ainda hoje, a principal área de produção agrícola do estado e já passava por um processo de modernização, baseado no trigo, desde a década de 1930. A revolução verde, a partir da década de 1960, acabou 
trazendo uma nova dinâmica, utilizando a estrutura pré-existente, só que com um novo produto, a soja. Antes de analisar a dinâmica que a soja trouxe para a agricultura da mesorregião, é importante ressaltar algumas características que a tornaram referência na modernização agrícola no país.

A princípio, deve-se analisar o âmago do desenvolvimento da atividade agrícola. Desse modo, para existir agricultura, necessariamente, têm-se dois condicionantes agrícolas: os naturais e os humanos. O equilíbrio entre esses dois fatores resultará na agricultura, ou seja, a agricultura só se desenvolve em determinada região se ambos os condicionantes estiverem presentes. Diante disso, a mesorregião noroeste era a única região do país com possibilidade de desenvolver a agricultura de clima temperado (condicionante natural) e que comportava um contingente populacional acostumado com as variedades desse clima (trigo, soja, arroz, milho, aveia, cevada).

Dentro dessa perspectiva, a mesorregião noroeste do Rio Grande do Sul desenvolveu a agricultura de forma diferente da praticada no restante do país. Impossibilitada, devido aos condicionantes naturais, de produzir em larga escala café e cana-de-açúcar, como no restante da agricultura tropical brasileira, essa região apoiou-se nas culturas do trigo, do milho e, posteriormente, da soja, desenvolvendo assim sua agricultura. Nota-se que a mesorregião noroeste não apresentava os condicionantes naturais para produzir as variedades da agricultura de clima tropical, mas dispunha de todos os condicionantes para produzir as variedades da agricultura de clima temperado.

\section{A soja: expressão máxima da revolução verde na mesorregião noroeste}

O pacote tecnológico da revolução verde transformou toda a agricultura brasileira e introduziu um novo produto na agricultura mesorregional, que, posteriormente, transformaria e expandiria todo o sistema moderno de produção. É nesse sentido que a revolução verde no Brasil foi, em muitos casos, confundida com o início da produção de soja na mesorregião noroeste do Rio Grande do Sul. A soja germinou de forma pioneira nos campos da mesorregião noroeste e, contemporaneamente, tornou-se um dos principais produtos do agronegócio brasileiro, pois era o produto competitivo que faltava para a agricultura nacional. Além disso, tinha boa produtividade e uma demanda crescente no mercado internacional. Era uma 
alternativa de verão que possibilitava duas safras anuais: uma de trigo no inverno e outra de soja no verão.

A soja encontrou na mesorregião noroeste um clima semelhante ao encontrado no centro-sul dos Estados Unidos, local de origem das primeiras sementes. Nesse sentido, segundo Kiihl e Calvo, "[...] os primeiros materiais [soja] (Bragg; Davis, etc.) cultivados em escala comercial no Rio Grande do Sul foram resultado de introdução de cultivares norte-americanos, [...] vindas de programas de melhoramento dos estados da Flórida, Mississipi e Carolina do Norte" (2008, p. 206).

A tecnologia da revolução verde também possibilitava ao produtor grande flexibilização tecnológica, pois com as mesmas máquinas (fazendo algumas adaptações) era possível cultivar uma ampla variedade de cultivares, assim, o produtor que adquirisse o maquinário para produzir trigo (cultivo e colheita) poderia produzir milho, aveia, cevada e soja. Dessa forma, o investimento feito por produtores da mesorregião para produzir trigo podia ser direcionado, com facilidade, para a produção da soja.

Outro elemento que influenciou para a consolidação da soja foi sua maior lucratividade em relação às outras culturas, em virtude da formação do mercado internacional da soja. Como os Estados Unidos eram o principal produtor mundial na época, o preço tendia a cair nos períodos de comercialização da safra norte-americana no mercado internacional e, consequentemente, subir nos períodos em que não havia a safra norte-americana. A safra de soja na mesorregião coincidia com a entressafra no mercado internacional, portanto, com as cotações mais altas do produto no mercado internacional.

A produção brasileira (por ser ainda pequena) não chegava a influenciar na demanda do produto no mercado internacional, menos ainda na cotação. Isso possibilitava aos produtores preços maiores para a soja produzida no Brasil, pois eles se beneficiavam da conjuntura internacional, altamente favorável para a comercialização do produto. O país aumentou sua participação no mercado mundial, de 1,64\%, em 1968, para 8,28\%, em 1973 (CONCEIÇÃO, 1986). A Tabela 1 mostra como a revolução verde, por meio da soja, impactou de forma direta a produção agrícola da mesorregião noroeste, consolidando-a, sem dúvida, como a principal região produtora de grãos do Brasil no século XX. No Rio Grande do Sul, a mesorregião noroeste, se comparada com outras mesorregiões do estado (Tabela 1), detinha a liderança isolada, produzindo, em média, 73,98\% de soja, 72,23\% de trigo e 59,61\% de milho. Apesar de a região, na década de 1970, ter na grande região centro-oeste paranaense uma adversária produtiva, ainda mantinha os melhores índices de participação na produção nacional de grãos, em média, alcançava 34,05\% 
da produção brasileira de soja, 49,78\% do trigo e 8,43\% do milho. Com esses dados, chega-se à constatação, no mínimo peculiar, de que a mesorregião noroeste, com um território ínfimo, em comparação ao território continental brasileiro (a mesorregião representa $0,82 \%$ do território nacional), era a principal região produtora de grãos do país. Esse é um dado impressionante, pois, com menos de 1\% do território brasileiro, a mesorregião representava quase a metade da produção brasileira de grãos.

Tabela 1 - Participação da produção mesorregional do Rio Grande do Sul e do Brasil na década de 1970 (em percentual)

\begin{tabular}{l|r|r|r}
\hline \multicolumn{1}{c|}{ Mesorregiões gaúchas } & Soja (\%) & Trigo (\%) & Milho (\%) \\
\hline Mesorregião noroeste & 73,98 & 72,23 & 59,61 \\
Mesorregião nordeste & 2,37 & 2,29 & 10,91 \\
Mesorregião centro-ocidental & 6,49 & 6,42 & 2,64 \\
Mesorregião centro-oriental & 5,29 & 2,69 & 9,27 \\
Mesorregião metropolitana & 2,12 & 0,45 & 6,71 \\
Mesorregião sudoeste & 5,96 & 13,86 & 2,03 \\
Mesorregião sudeste & 3,79 & 2,05 & 8,83 \\
Rio Grande do Sul & 100 & 100 & 100 \\
Brasil & 34,05 & 49,78 & 8,43 \\
\hline
\end{tabular}

Fonte: Instituto de Pesquisa Econômica Aplicada. Disponível em: <http://www.ipeadata.gov.br/>.

A Tabela 2 apresenta uma síntese dos acontecimentos econômicos desencadeados pela revolução verde na mesorregião noroeste. É possível observar que houve uma elevada valorização do preço da terra, muito disso deu-se por que passou a ser melhor aproveitada, ou seja, com a tecnologia da revolução verde era possível um melhor aproveitamento da terra e uma maior destinação de áreas para a agricultura. Isso acarretava, dentre outros aspectos, maior valorização da propriedade, e é exatamente, como se constata nos dados da Tabela 2 , o que ocorreu. Na mesorregião noroeste, o valor total da terra, que em 1970 era $\mathrm{R} \$ 8.442 .891,91$, subiu para $\mathrm{R} \$ 24.259 .075,29$ em 1975, estabilizando-se em 1980, e voltando a elevar-se em 1985. Ressalta-se que entre 1970 e 1975, em um intervalo de apenas cinco anos, houve uma variação percentual de 187,33\% no valor total da terra na mesorregião.

Outro dado importante da Tabela 2 refere-se ao aumento do valor dos bens agropecuários totais, que ocorreu devido ao investimento contínuo em máquinas e equipamentos, insumos químicos modernos, sementes e estrutura agrícola como um todo. O valor, que era de $\mathrm{R} \$ 13.517 .425,21$, aumentou rapidamente para $\mathrm{R} \$ 33.320 .827,62$, com um aumento percentual de 146,50\% em cinco anos. Esse 
aumento no valor da terra e dos bens agropecuários veio acompanhado de um aumento nos investimentos totais realizados, que passaram de $\mathrm{R} \$ 639.187,95$, em 1970, para R\$1.066.620,48, em 1975. Os dados da Tabela 2, antes de tudo, remetem ao impacto inicial dos dispêndios com a propagação do pacote tecnológico da revolução verde. Com a introdução da soja, a agricultura mudou a relação entre o agricultor e a terra, e desse com o mercado. Mas qual era a verdadeira importância da mesorregião noroeste no desenvolvimento da cultura (soja)?

Tabela 2 - Valor total da terra, próprias, arrendadas ou ocupadas por mesorregião

\begin{tabular}{|c|c|c|c|c|}
\hline & 1970 & 1975 & 1980 & 1985 \\
\hline \multicolumn{5}{|l|}{ Valor total da terra } \\
\hline Mesorregião noroeste & $8.442 .891,91$ & $24.259 .075,29$ & $21.471 .142,59$ & $34.332 .199,31$ \\
\hline \multicolumn{5}{|c|}{ Valor dos bens agropecuários totais } \\
\hline Mesorregião noroeste & $13.517 .425,21$ & $33.320 .827,62$ & $33.799 .366,09$ & $52.588 .830,51$ \\
\hline \multicolumn{5}{|c|}{ Investimentos totais realizados - agropecuária } \\
\hline Mesorregião noroeste & $639.187,95$ & $1.066 .620,48$ & $1.098 .586,70$ & $1.081 .394,31$ \\
\hline
\end{tabular}

Fonte: Instituto de Pesquisa Econômica Aplicada. Disponível em: < http://www.ipeadata.gov.br/>.

A Figura 2 responde a essa questão, apesar de os dados referirem-se ao estado. Como pode ser observado na Tabela 1 , somente a mesorregião noroeste era responsável por $73,98 \%$ da produção estadual e por 34,05\% da produção nacional. Então, apesar de não existirem dados estratificados específicos da mesorregião, pode-se inferir que a maior parte da produção de soja era mesorregional. Portanto, observando-se a Figura 2, constata-se, de forma clara, que, até o início da década de 1970, a mesorregião produzia sozinha praticamente toda a soja do país, tendo a grande região centro-oeste paranaense como rival a partir da década de 1970. Essa grande região paranaense foi colonizada em grande parte por agricultores oriundos da mesorregião noroeste sul-rio-grandense, que levaram consigo esse modelo para o oeste paranaense e catarinense. Essa característica dos produtores mesorregionais era muito importante, tanto que, em um trabalho da Embrapa sobre a propagação da soja pelo território nacional, é apontada como uma das causas do sucesso do espírito pioneiro dos gaúchos.

Nas palavras dos pesquisadores Kiihl e Calvo, da Embrapa, o estado do Rio Grande do Sul "não foi somente o berço do cultivo da soja no Brasil, mas também o da formação de uma legião de sojicultores que, rapidamente, migraram para outros estados da Nação em busca de terras mais baratas para o cultivo da espécie" (2008, p. 203). Ainda, elevaram o "espírito aventureiro dos gaúchos aliado à disposição, à capacidade de trabalho, ao cultivo de valores e à perseverança, foi fundamental para o sucesso da soja nos trópicos do Brasil [...]" (2008, p. 203). 
Figura 2 - Expansão da soja na revolução verde

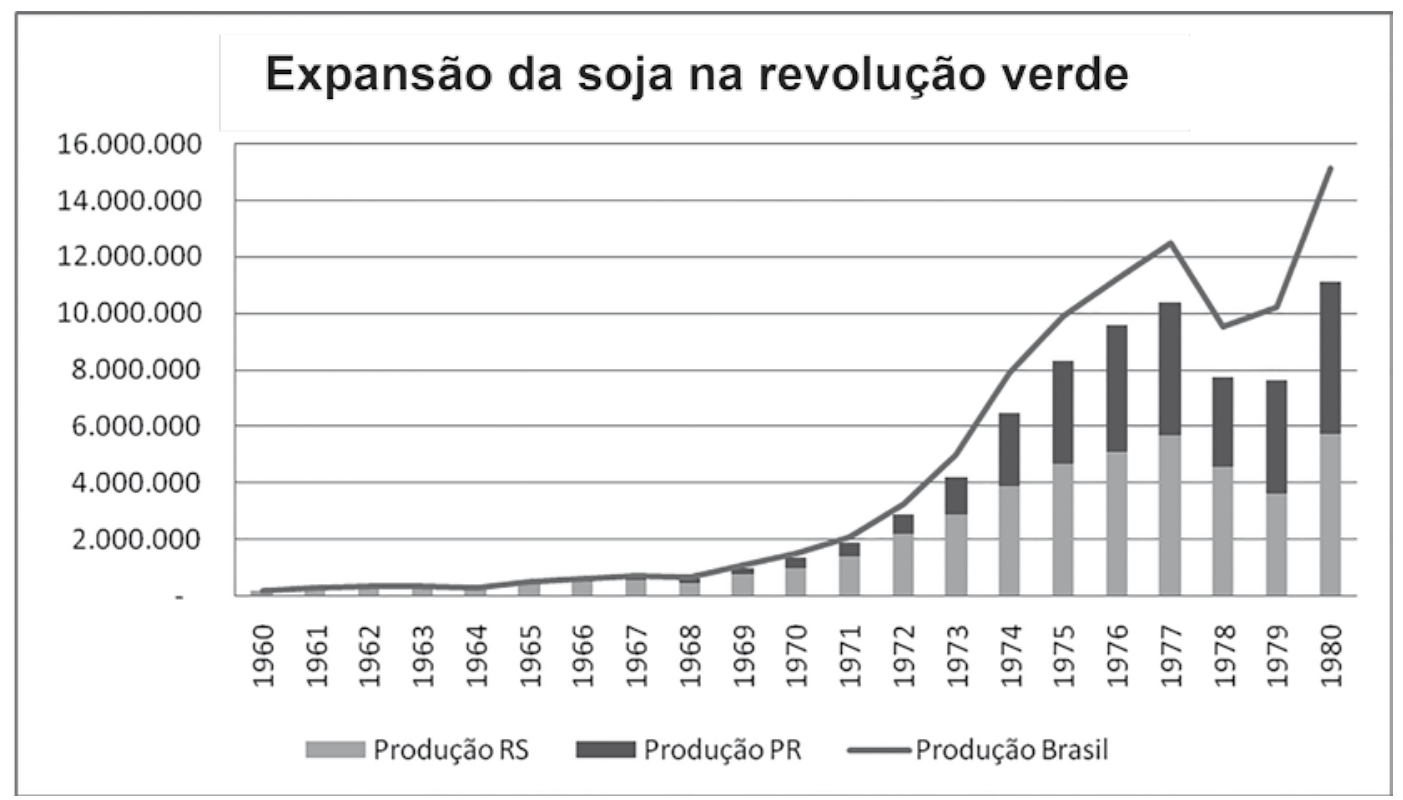

Fonte: Instituto de Pesquisa Econômica Aplicada. Disponível em: <http://www.ipeadata.gov.br/>.

\section{Transformações agrícolas e a formação do complexo agroindustrial na mesorregião noroeste com a revolução verde}

A partir da consolidação da revolução verde, novas estruturas foram criadas com o objetivo de facilitar a modernização agrícola, outras foram modificadas e adequadas para melhor atender às demandas modernizantes dos produtores. Com a implementação desse modelo, aumentou também o ritmo de crescimento das indústrias que se relacionavam com a agricultura, indústrias especializadas em fornecer insumos e com porte econômico para financiar, ou forçar, o Estado a lançar linhas de crédito subsidiadas para seus produtos. Tanto as indústrias que forneciam insumos modernos como as que processavam a produção requeriam a especialização produtiva de um grande número de produtores rurais, pois combinaram a atividade agrícola com os mercados monopólicos, ou claramente oligopolizados. 
Compreendendo um emaranhado complexo industrial, caracterizando-se com subsetores produtivos "a montante" e "a jusante", capazes de se integrarem horizontalmente com uma série de outros subsetores nessa mesma ótica, diversificando os produtos e os riscos (ALBUQUERQUE, 1984).

Concomitantemente à revolução verde, surge o complexo agroindustrial. A ideia básica por trás do complexo agroindustrial é a de que não pode haver vazios na atividade produtiva, pois "[...] setores considerados vazios quando ocupados provocam o surgimento de outras atividades para frente e para trás formando uma cadeia produtiva" (FAJARDO, 2008, p. 32). Pensando nesse pressuposto, pode-se analisar as modificações ocorridas nas estruturas agrícolas da mesorregião noroeste para a formação do complexo agroindustrial da soja. É claro que a maioria dos setores já havia sido "pré-fabricada" com a revolução verde, mas alguns vazios foram desenvolvidos ou instalados na mesorregião noroeste e ainda servem de referência para a agricultura brasileira.

Uma das estruturas agrícolas criadas especialmente para suprir a demanda de tecnologia moderna da nova dinâmica agrícola mesorregional foi o setor de máquinas e implementos agrícolas, que formou um dos mais importantes arranjos produtivos estaduais. Os primeiros passos foram dados nas décadas de 1940 e 1950, mas foi nas décadas de 1960 e 1970 que tomou a forma de um arranjo produtivo. Essas empresas surgiram da necessidade de adaptar e dar a manutenção adequada aos equipamentos importados, já que as importadoras não se preocupavam com a reposição de peças, o que abriu espaço para a pequena indústria local, que passou a suprir essa necessidade (TEDESCO et al., 2005). A indústria local especializou-se na fabricação de implementos agrícolas, como arados, grades, plantadeiras, na época, equipamentos sem muita tecnologia embarcada e, muitas vezes, uma adaptação dos produtos importados. Entretanto, houve também a associação com o capital internacional para a produção de tratores e colheitadeiras, como a da JLC com a John Deere e da Ideal com a Massey Ferguson.

Em estudo sobre o arranjo de máquinas e implementos agrícolas no Rio Grande do Sul, Tatsch (2008) faz um levantamento das principais áreas, dentro da mesorregião noroeste, produtoras de máquinas e implementos agrícolas. Na cidade de Santa Rosa e arredores, desenvolveram-se firmas menores, geralmente fornecedoras de peças e componentes, e as principais empresas produtoras de tratores e colheitadeiras do país (ACGO e John Deere). Na região dos municípios de Passo Fundo, Carazinho e Não-Me-Toque, prevaleceram as empresas de maquinário e implementos agrícolas (Semeato, Stara, Jan, Max, Gihal). Na região de Ijuí, prevaleceram as empresas do ramo de equipamentos agrícolas, além de empresas de 
silos de armazenagem (Imasa, Kepler Weber). Contemporaneamente, a mesorregião noroeste é o principal polo de pesquisa e desenvolvimento de máquinas e implementos agrícolas do Brasil. Segundo Silva Junior e Neumann, o Rio Grande do Sul é "responsável por 55\% das 8.407 colheitadeiras produzidas no país em 2008 e de $52 \%$ dos 66.504 tratores produzidos no mesmo ano" (2009, p. 2).

Outra estrutura agrícola que sofreu grande transformação para preencher as lacunas do complexo agroindustrial foram as cooperativas da mesorregião noroeste. Criadas na década de 1950 para a promoção da cultura do trigo e como instituições representativas dos produtores, com a revolução verde e o surgimento da soja, passaram a representar uma gama maior de produtores, passando de cooperativas tritícolas a multicooperativas. Para Siqueira, com o processo de modernização da agricultura, a concentração de produtores em cooperativas serviu "aos propósitos do Estado brasileiro na implementação da chamada 'Revolução Verde', facilitando a difusão de novas tecnologias de produção agrícola, capazes de aumentar a produtividade física e econômica das lavouras" (2001, p. 43).

A cooperativa representava, então, não só os produtores rurais, mas a modernização agrícola em si, o crédito e as novas tecnologias. $O$ crédito, abundante, era repassado aos produtores por intermédio das cooperativas, que ainda induziam a compra de insumos, principalmente os químicos, as máquinas e os equipamentos, disseminando a incorporação das novas tecnologias entre um número cada vez maior de produtores. Foi o aumento representativo das cooperativas que difundiram o uso do crédito, pois os bancos oficiais "provavelmente não teriam condições operacionais de levar à grande maioria dos pequenos agricultores os financiamentos necessários ao incremento da produção, pela falta de procura em razão do desconhecimento, ou pelo fato de serem, até então, apenas microprodutores" (TEDESCO et al., 2005, p. 143). A cooperativa era a ligação do produtor com o crédito, e desse com a tecnologia e a modernidade.

De outro modo, o Estado confiava na cooperativa, pois ela representava a união de uma grande quantidade de pequenos, médios e grandes produtores. Para o Estado, apoiar a cooperativa era como ajudar a todos os produtores, sem distinção do porte de sua propriedade. A cooperativa concentrava os produtores, estimulando assim a concorrência e possibilitando a economia de mercado, ou seja, as cooperativas uniam os produtores, que, sozinhos, não conseguiriam participar da comercialização (SIQUEIRA, 2001).

O crédito facilitado, fluindo da cooperativa para o produtor, também acontecia do governo para as cooperativas. Esse crédito abundante possibilitou a implementação de um projeto agroindustrial pelas cooperativas, assim "é que, do simples 
propósito de moer trigo, fixado como meta no início de suas operações, já no começo de 1960, [estabeleceram-se] como linha de atuação o beneficiamento da produção agropecuária em geral" (TEDESCO et al., 2005, p. 142).

Benetti (1985), em seu artigo Endividamento e crise no cooperativismo empresarial do Rio Grande do Sul, demonstra claramente que o resultado imediato das transformações ocorridas nas cooperativas foi o aumento da gama de funções desempenhadas pelas cooperativas. Em última instância, o produtor cooperativado foi transformado em sócio empresarial de um complexo industrial, que não mais se restringia a receber e estocar a produção. Agora as cooperativas processavam essa produção agrícola, desenvolvendo unidades fabris e convertendo-se em cooperativas múltiplas agroindustriais. Assim, diversificaram seu portfólio produtivo, livrando-se das amarras da triticultura, construindo moinhos, refinarias de soja (produção de óleo vegetal), frigoríficos para suínos e aves e fábricas de ração. Para construir esse conglomerado, tiveram de se alinhar ao capital de terceiros, não cooperativado.

Como eram cooperativas tritícolas, pressupunha-se que os primeiros investimentos na agroindustrialização fossem aplicados no processamento industrial do trigo, no entanto, os recursos foram empregados principalmente com a soja. Desse modo, as cooperativas transformaram-se em um centro dinâmico da propagação da agricultura moderna, irradiando não só tecnologia, como também serviços auxiliares de assistência creditícia, seguros, câmbio, contratos futuros, em suma, era um agente capitalista dentro de uma associação cooperativa. As cooperativas assumiram os setores vazios do complexo agroindustrial e criaram estrutura para preenchê-lo, atuando no mercado a montante, como revendedora de insumos (fertilizantes, agrotóxicos), e no mercado a jusante, processando a produção agrícola.

\section{Impactos socioeconômicos na mesorregião noroeste no período}

Com a revolução verde e a criação do complexo agroindustrial, houve transformações em toda a estrutura agrícola da mesorregião noroeste, que extrapolaram o setor agrícola e impactaram diretamente a economia e a sociedade mesorregional. O uso intensivo de máquinas, agentes químicos e o financiamento da produção acentuavam a acumulação de capital e os investimentos em equipamentos agrícolas. Na mesorregião não foi diferente, com o crédito obtido ou com parte do capital acumulado, investiu-se na aquisição de equipamentos e insumos agrícolas 
modernos criando novos nichos de mercado, como a produção de máquinas e implementos agrícolas e a revenda de insumos para a agricultura. Isso é verificável na Tabela 3, que mostra os valores estimativos concedidos em financiamentos na mesorregião noroeste com base nos dados dos censos agropecuários de 1970, 1975 e 1980 .

Tabela 3 - Valores estimados de financiamentos agrícolas na mesorregião noroeste

\begin{tabular}{|c|c|c|c|}
\hline & \multicolumn{3}{|c|}{ Origem } \\
\hline & Total $^{*}$ & Governo* & Outras fontes* \\
\hline Mesorregião noroeste 1970 & $2.151 .402,80$ & $1.996 .850,37$ & $148.803,73$ \\
\hline Mesorregião noroeste 1975 & $7.244 .238,02$ & $6.696 .550,20$ & $547.692,13$ \\
\hline \multirow{3}{*}{ Mesorregião noroeste 1980} & $8.734 .271,18$ & $8.121 .633,69$ & $612.633,54$ \\
\hline & \multicolumn{3}{|c|}{ Finalidade } \\
\hline & Investimento* & Custeio* & Comercialização* \\
\hline Mesorregião noroeste 1970 & $369.723,09$ & $717.887,14$ & $129.116,75$ \\
\hline Mesorregião noroeste 1975 & $650.161,82$ & $3.332 .578,90$ & $78.785,88$ \\
\hline Mesorregião noroeste 1980 & $430.859,34$ & $5.297 .635,21$ & $38.029,81$ \\
\hline
\end{tabular}

Fonte: Censo agropecuário, 1970, 1975 e 1980 .

* Valores em mil reais, corrigido para valores monetários de 2012.

Com base na Tabela 3, denota-se o aumento do dispêndio em crédito agrícola na mesorregião e o peso da participação do governo como financiador da modernização (revolução verde) agrícola mesorregional. O dispêndio total de financiamento variou impressionantes 305,98\% ao longo da década de 1970, saindo de um total de $\mathrm{R} \$ 2.151 .402,80$, para $\mathrm{R} \$ 8.734 .271,18$. O que mais pesou nesse montante foi o custeio agrícola, destinado a financiar as despesas do ciclo produtivo, tais como: insumos, tratos culturais, despesas com a colheita, beneficiamento, sementes certificadas, entre outras aplicações. Verifica-se com isso garantira compra da tecnologia da revolução verde, principalmente a aquisição de adubos, agrotóxicos e sementes.

Outro dado que pode ser observado na Tabela 3 é sobre a origem dos recursos. O governo entrou, em média, com $92,74 \%$ do dispêndio de crédito agrícola na mesorregião, segundo os censos agropecuários, em relação ao total no período estudado. Dado que comprova a ideia de que a política de crédito no Brasil estava orientada para impulsionar a modernização agrícola, havendo correspondência entre o crédito agrícola e as modificações encontradas na agricultura mesorregional no que diz respeito ao esforço de o Estado estabelecer uma ligação entre a indústria de bens de capital e insumos com a agricultura. O que se confirma com os dados da destinação dos recursos creditados, com o aumento do repasse dos valores de crédito para custeio, que se constata com o aumento do uso de insumos químicos 
(adubos, fertilizantes, agrotóxicos) e o crescimento do crédito para investimentos (compra de máquinas).

À medida que esse processo ocorria, outro fenômeno importante, relacionado à revolução verde, acontecia na mesorregião. Como indica Sitoe (2010, p. 45), à medida que ocorre a capitalização da agricultura e o uso cada vez mais intensivo de tecnologia, libera-se cada vez mais mão de obra rural para a indústria, e quando os trabalhadores não são mais absorvidos pelo mercado, criam-se os bolsões de pobreza nos centros urbanos. A liberação de um contingente de mão de obra rural, empregados rurais trocados pelo trator, pequenos produtores que não conseguiam financiar a aquisição da tecnologia ou antigos arrendatários, representava um grande desafio para a administração das cidades na mesorregião noroeste.

De acordo com Rückert, a cidade de Passo Fundo desenvolveu um cinturão da fome, "provocado pelo êxodo rural-urbano, emerge na cidade localizada numa das regiões agrícolas consideradas das mais avançadas do país" (2003, p. 173, grifo nosso). Segundo o autor, baseado em dados do jornal $O$ interior, um quinto da população do município era constituído:

[...] de desempregados e biscateiros que viviam em 69 vilas marginalizadas. Desse total a parcela mais significativa é composta por ex-minifundiarios e peões de lavoura que a crescente mecanização agrícola empurrou em direção à cidade. Por outro lado, as precárias condições de vida dessas vilas engendra os mais diversos problemas sociais como delinquência, prostituição e desagregação familiar (RÜCKERT, 2003, p. 173).

O quadro levantado por Rückert pode ser avaliado como consequência do êxodo rural em direção aos centros urbanos mesorregionais. Assim, com o aumento da produção agrícola e a utilização de terras anteriormente inutilizadas, elevou-se a renda agrícola com a produção de soja e a valorização do patrimônio agropecuário. À medida que isso ocorria, reduziam-se os latifúndios improdutivos, pois com a tecnologia e a mecanização era possível plantar grandes áreas de terra anteriormente subexploradas. Em consequência, houve uma transformação nos minifúndios subestruturados ou rudimentares em razão da subdivisão familiar (herdeiros), da valorização da terra (o grande produtor mecanizado comprava a pequena propriedade) e principalmente por não ter escala para a produção (pouca terra) (OLIVEIRA, 1985). Esse indício é perceptível nos dados estratificados dos censos agropecuários encontrados na Tabela 4. Percebe-se a consolidação do modelo agrícola da revolução verde na mesorregião, onde gradativamente diminuía a participação das pequenas propriedades e aumentava a das médias e grandes. Segundo Ohlweiler (1982), apenas as estratificações ${ }^{4}$ pelo tamanho da propriedade não conseguiam caracterizar a relação do produtor nela estabelecido. Pode-se ter uma pequena propriedade e o 
produtor estar com uma situação econômica muito estruturada, mas, no geral, é a partir da estratificação que se pode ter uma ideia aproximada das classes sociais rurais na época.

Tabela 4 - Intervalo de classes (ha) de estabelecimentos na mesorregião noroeste

\begin{tabular}{l|r|r|r|r|r|r|r}
\hline \multicolumn{1}{c|}{ Intervalo (ha) } & \multicolumn{1}{c|}{1960} & \multicolumn{1}{c|}{1970} & \multicolumn{1}{c|}{1975} & \multicolumn{1}{c|}{1980} & $60 / 70(\%)$ & $70 / 75(\%)$ & $75 / 80(\%)$ \\
\hline Menos de 1 a 10 & 41.462 & 81.366 & 69.509 & 78.266 & 96,24 & $-14,57$ & 12,60 \\
10 a menos de 50 & 106.957 & 125.681 & 115.245 & 114.706 & 17,51 & $-8,30$ & $-0,47$ \\
50 a menos de 200 & 13.461 & 13.593 & 14.497 & 26.743 & 0,98 & 6,65 & 84,47 \\
200 a menos de 1.000 & 2.510 & 3.331 & 3.473 & 3.721 & 32,71 & 4,26 & 7,14 \\
Mais de 1.000 & 388 & 356 & 397 & 382 & $-8,25$ & 11,52 & $-3,78$ \\
\hline
\end{tabular}

Fonte: Censo agropecuário, 1960, 1970, 1975 e 1980.

Com base nas estratificações feitas por Ohlweiler e com algumas modificações, foi elaborada a Tabela 4, na qual têm-se as indicações da realidade encontrada na mesorregião noroeste, apresentando as propriedades agrícolas da mesorregião, que são classificadas pelo seu tamanho (em hectares), e o número de estabelecimentos encontrados em cada intervalo nos censos agropecuários de 1960, 1970, 1975 e 1980. Nota-se também que as propriedades pertencentes aos latifundiários (200 ha a 1.000 ha) aumentaram constantemente sua participação, com destaque para o aumento de 32,71\% no final da década de 1960 (60\% a 70\%). A burguesia rural, formada por médios e grandes proprietários ( 50 ha a 200 ha), teve um aumento de $84,47 \%$ no final da década de 1970 , havendo, inclusive, uma tendência na redução de estabelecimentos de camponeses médios (10 ha a 50 ha), comprovando a concentração fundiária e a tendência de êxodo rural do modelo da revolução verde.

Já os estabelecimentos camponeses pobres, entre 1 ha a 10 ha, apesar de apresentarem um grande aumento no final da década de 1960, 96,24\%, em relação ao censo de 1960, mantiveram-se em uma trajetória de queda, estabilizando-se posteriormente. Essa situação é resultado, em parte, da tradição familiar do colono gaúcho de abrir novas áreas para seus descendentes herdeiros. Essa dinâmica entrou em colapso quando se extinguiram as áreas para novas colônias no Rio Grande do Sul. Aos filhos dos pequenos colonos restaram três opções: redividir a terra de seus pais, fato muito corriqueiro na época, emigrar para outros estados, em que novas áreas estavam sendo implantadas, ou tentar a sorte na cidade. Nessas três opções é que se encontra uma particularidade, até certo ponto inteligente, mas perversa, de como foi conduzida a revolução verde no Brasil.

Como foi a última área colonizada no estado, a mesorregião nordeste extinguiu a dinâmica de abrir novas colônias em áreas vazias no Rio Grande do Sul. Assim, 
em muitos casos, passou-se a fracionar a terra pertencente ao núcleo familiar para acomodar todos os descendentes. As propriedades que inicialmente tinham um tamanho razoável, com capacidade para prover o sustento de toda a família, com o fracionamento entre os descendentes, tornaram-se minifúndios. Portanto, com o contínuo fracionamento, onde antes havia uma propriedade de tamanho médio, entre 10 e 50 hectares, agora existiam inúmeras pequenas propriedades, incapazes de sustentar e manter uma família exclusivamente com o cultivo da terra.

Os dados apresentados na Tabela 5 permitem uma melhor percepção do processo de fracionamento que ocorreu nas pequenas propriedades da mesorregião noroeste com o advento da revolução verde. É possível constatar que o fracionamento era mais acentuado nas propriedades de menor área, e não tão acentuado nas de maior porte. Deve-se esse fato à subdivisão da propriedade entre os membros da família, mas também à tecnologia empregada no modelo da revolução verde. O ponto tecnológico é essencial para entender porque havia a tendência de permanecer no mercado as propriedades maiores e excluir as pequenas. A tecnologia empregada na revolução verde, baseada na mecanização e na utilização de produtos químicos, que, apesar de ser viável a todos os produtores, independentemente do tamanho das propriedades, não era acessível a todos, pois era cara. Naturalmente, com uma propriedade maior, era mais fácil acumular recursos financeiros ou dar garantias (terras, imóveis) para a aquisição do insumo.

Tabela 5 - Fracionamento dos estabelecimentos na mesorregião noroeste

\begin{tabular}{l|r|r|r|r|r|r|r}
\hline \multicolumn{1}{c|}{ Intervalo (ha) } & \multicolumn{1}{c|}{1960} & \multicolumn{1}{c|}{1970} & \multicolumn{1}{c}{1975} & 1980 & $60 / 70(\%)$ & $70 / 75(\%)$ & $75 / 80(\%)$ \\
\hline Menos de 1 a 10 & 353 & 2.578 & 2.059 & 3.366 & 630,31 & $-20,13$ & 63,48 \\
1 a menos de 2 & 1.639 & 7.666 & 4.626 & 6.228 & 367,72 & $-39,71$ & 34,75 \\
2 a menos de 5 & 13.761 & 29.530 & 23.792 & 26.471 & 114,59 & $-19,43$ & 11,26 \\
5 a menos de 10 & 25.709 & 41.592 & 39.036 & 42.201 & 61,78 & $-6,15$ & $-9,55$ \\
10 a menos de 20 & 53.324 & 69.210 & 62.598 & 64.265 & 29,79 & $-9,55$ & 2,66 \\
\hline
\end{tabular}

Fonte: Censo agropecuário 1960, 1970, 1975 e 1980.

As consequências imediatas da revolução verde na estrutura agrícola na mesorregião noroeste foram a criação do complexo agroindustrial, a liberação de mão de obra rural e o fracionamento de pequenas propriedades, elementos que constituíram um cenário ideal para conflitos agrários, em torno da luta pela terra e reforma agrária. Luta que já estava germinando com os assentamentos propostos pelo governador Leonel Brizola, em período anterior ao golpe militar. É nesse ponto que entra novamente a figura do governo militar e da Fundação Rockefeller na agricultura mesorregional. 
O governo ditatorial suplantou todo e qualquer movimento social que estava eclodindo, extinguindo principalmente o Movimento dos Agricultores Sem Terra, grupo que contava com grande apoio político-partidário no estado. Em contrapartida, o governo criou o Estatuto da Terra, "feito para apaziguar as tensões sociais no campo [...] [tornando-se] o principal instrumento, tanto da promoção da Empresa Rural como dos deslocamentos populacionais" (RÜCKERT, 2003, p. 144).

A implementação de uma "reforma agrária", com a ajuda da Fundação Rockefeller, surgiu para aliviar a pressão por terra na mesorregião noroeste e aproveitar o conhecimento agrícola (capital humano) dos agricultores. O governo militar passou a incentivar a migração interna e a criar novas colônias no centro-oeste brasileiro. Um exemplo prático dessa política de transferência consistia em utilizar a metodologia educacional da revolução verde. Primeiramente, orientavam-se os produtores a aumentar sua produtividade via extensão rural e Clubes 4-S. Não obtendo resultado, principalmente em razão do diminuto tamanho da propriedade para o desenvolvimento do modelo, o Instituto Nacional de Colonização e Reforma Agrária orientava o grupo a organizar uma cooperativa de colonização, que promoveria a transferência dos agricultores para o centro-oeste. $\mathrm{Na}$ formação da cooperativa de colonização:

[...] o pré-requisito para a admissão de sócio é de que ele seja proprietário de, pelo menos 5 ha. Tal pequena fração de terra é, então, suficiente para servir de pagamento do sinal na compra de 400 ha, no Mato Grosso. A cooperativa, com apoio do crédito fundiário do Banco do Brasil, repassa o financiamento da compra de terra para o camponês associado. Nesse meio tempo, de 1976 em diante, a cooperativa instala vários escritórios de recrutamento de camponeses em todo o Alto Uruguai e Planalto Médio [regiões dentro da Mesorregião Noroeste]. Os camponeses pobres passam, então, a vender suas propriedades aos vizinhos mais próximos ou a capitalistas de agricultura para se tornarem aptos a integrar os projetos de colonização no Centro-Oeste. A cooperativa passa, então, a ampliar várias frentes na fronteira agrícola, rumo ao norte, no então Estado de Mato Grosso (RÜCKERT, 2003, p. 153-154, grifo do autor).

A ação de colonização do centro-oeste brasileiro foi primeiramente concebida pela Fundação Rockefeller, por meio de seu braço atuante no país, a American International Association for Economic and Social Development, na década de 1960. A partir da década de 1970, as cooperativas mesorregionais, agora multicooperativas, apoiadas pelo governo, fizeram projetos de colonização para assentar agricultores associados sem-terra ou filhos de agricultores. Um exemplo foi o projeto de colonização realizado pela Coopasso, multicooperativa de Passo Fundo que implementou um projeto de colonização no estado de Goiás, dentro do projeto 
Alto Paraíso. A Coopasso iria, inicialmente, ocupar uma área de 98 mil hectares e transferir a terra aos agricultores que estavam dentro de sua área de atuação. Os agricultores seriam selecionados oportunamente, levando-se em conta uma série de requisitos, o essencial era ter tradição na agricultura (TEDESCO et al., 2005, p. 188).

O Estado brasileiro via no produtor gaúcho, como um todo, um modelo ideal para colonizar a vastidão do cerrado, pois já estava acostumado com a agricultura de mercado e constituía-se em um expressivo exército de mão de obra disposta a migrar. ${ }^{5}$ "Para atingir os objetivos, o próprio Estado nacional, em conjunto com os grupos econômicos privados interessados, traçou as políticas que possibilitassem a transferência dessa população para as novas áreas" (ALVES, 2005, p. 50), constituindo, assim, um novo desdobramento do modelo da revolução verde da mesorregião noroeste.

Contudo, o produtor mesorregional foi escolhido para representar o modelo, pois ele conseguia congregar em torno de si a face mais desejada pelo governo militar, a agricultura moderna. Então, a pressão por terra era diluída com a transferência de um montante cada vez maior de pequenos produtores mesorregionais para o centro-oeste brasileiro. Mesmo assim, a questão da terra na mesorregião noroeste ficou encoberta sob a "cortina de ferro" da ditadura. Assim que essa caiu, iniciaram-se novamente os movimentos pela terra com o Movimento dos Trabalhadores Rurais Sem Terra, movimento originariamente mesorregional.

O exposto vem expressar uma grande contradição, pois junto com o aumento da produção, da área cultivada, da produtividade, da tecnologia empregada, em contrapartida, aumentavam também os índices de desempregados, de marginalizados e de deslocados. Com a introdução do modelo moderno de produção, os proprietários de minifúndios acabaram não conseguindo financiar as novas tecnologias, até porque não tinha muito sentido investir em novas tecnologias, pois eles não possuíam terra suficiente para aproveitá-las.

Com a abertura de novas áreas escasseando e com a valorização da terra, tornou-se inevitável para os pequenos produtores o desejo de entrar no novo modelo. Então, eles acabaram por vender seus lotes para os produtores médios ou grandes, que tinham condições de retirar maior retorno desse empreendimento, o que os forçou a migrar ou a ir tentar a vida nos centros urbanos. À medida que a revolução verde ia modernizando a agricultura, liberava também a mão de obra, que era encaminhada para as novas regiões agrícolas do centro-oeste brasileiro.

Há controvérsias inerentes à revolução verde, bem aceita por governos, economistas e grande parte dos agricultores, que viram a oportunidade de aumentar 
sua área plantada e diminuir seus custos totais, principalmente quanto ao valor da mão de obra. Além disso, a modernização estabeleceu relações mais complexas de trocas e criou um "expurgo no campo", gerando um passivo social que sempre estará atrelado ao seu conceito.

Para o Brasil, a revolução verde trouxe a possibilidade de melhorar a empregabilidade do seu espaço agrícola, germinando a tecnologia necessária para a definitiva transformação da agricultura "tropical" brasileira. Claro que todo esse processo se deu à custa da degradação ambiental e da marginalização da população que não se adaptasse aos métodos e técnicas da revolução verde. Para a mesorregião noroeste, a revolução verde significou a transformação do seu espaço agrícola, servindo de laboratório para o projeto maior apresentado para a agricultura do país.

\section{Considerações finais}

A mesorregião noroeste foi a primeira região agrícola produtiva brasileira a receber, por um longo período de tempo (década de 1930 até a de 1980), incentivos contínuos do governo, seja estadual, seja federal, para aumentar a produção. Os agentes governamentais, percebendo o potencial geográfico e climático da mesorregião, acreditavam que seria possível desenvolver a agricultura de forma diferente da existente no restante do território brasileiro. Esses incentivos acabaram gerando um potencial modernizante, muito bem utilizado com a chegada da revolução verde a partir da metade da década de 1950.

Com a revolução verde, na década de 1960, a soja constituiu-se na principal cultura agrícola mesorregional e, posteriormente, nacional. Nesse período, houve também a consolidação do complexo agroindustrial, transformando todo o complexo produtivo e tornando a agricultura um setor subsidiário da indústria em expansão. Nesse sentido, a revolução verde representou a consolidação da agricultura moderna na mesorregião noroeste como fonte de renda e prosperidade econômica, utilizando para isso todo um complexo sistema de apoio financeiro e tecnológico, apoiado em um sistema de suporte técnico e educacional. Os resultados imediatos foram a monocultura, a massificação produtiva, a dependência financeira e tecnológica e o endividamento do produtor rural.

Outra característica marcante foi a transformação ocorrida nas cooperativas, que passaram de representantes dos produtores a especuladores da produção agrícola. Seu foco mudou da comercialização para a industrialização, transformando-se em componente importante do complexo agroindustrial mesorregional, 
preenchendo lacunas ao processar grande parte da produção agrícola em plantas industriais criadas para tal. Ocorreu também a reorganização de seus interesses, pois não seria mais possível defender o aumento do preço dos produtos agrícolas com tanto afinco, já que isso prejudicaria sua própria produção agroindustrial.

A revolução verde, por se tratar de um modelo agrícola capitalista extremamente excludente, quando aplicada na agricultura da mesorregião aprofundou $o$ processo de êxodo rural, identificado em duas vias: em um primeiro momento, houve a evasão de posseiros, pequenos produtores e pequenos arrendatários para os centros urbanos mesorregionais, engrossando os cinturões de pobreza a as mazelas sociais, em um segundo momento, ocorreu a criação de projetos colonizadores que utilizavam a mão de obra agrícola qualificada de pequenos e médios proprietários transferidos para as novas colônias agrícolas no centro-oeste brasileiro.

Como o novo modelo agrícola da revolução verde não conseguia englobar todos os produtores rurais da mesorregião noroeste (micro e pequenos produtores), foi implementado um programa de colonização e reaplicado o modelo com os "resíduos" dessa instalação. Os produtores que não conseguiam adaptar-se às novas técnicas e às novas tecnologias, geralmente por não ter terra suficiente, eram imediatamente transferidos para as novas colônias abertas no oeste paranaense ou no centro-oeste brasileiro. Essa corrente migratória levou consigo o modelo e acelerou o processo de implantação da revolução verde no país. 


\title{
Green revolution and modernization in agricultural mesoregion northwest Rio Grande do Sul - 1960/1970
}

\begin{abstract}
This article goes back to the beginning of the agricultural production specialization in mesoregion Northwest Rio Grande do Sul, with the introduction of the technology of the Green Revolution package, emphasizing the transformations in agriculture mesoregion Northwest Rio Grande do Sul The study is justified. the historical relevance of the theme for mesoregion in question, where agriculture was the first and main form of economic activity and the changes occurring in it changed the whole economic, social and agrarian system. The paper aims to demonstrate how occurred the formation and consolidation of the agricultural modernization program, represented by the Green Revolution, the mesoregion Northwest, and the principle of model dissipation to other regions of the country, analyzing the period that encompasses the decades 1960-1970 .
\end{abstract}

Keywords: Green revolution. Agricultural modernization. Mesoregion northwest.

\section{Revolución verde y modernización en mesorregião noroeste Rio Grande do Sul - 1960/1970}

\begin{abstract}
Resumen
En este artículo se remonta al comienzo de la especialización de la producción agrícola en meso noroeste de Rio Grande do Sul, con la introducción de la tecnología de la Revolución Verde, haciendo hincapié en las transformaciones en la agricultura meso noroeste de Rio Grande do Sul El estudio está justificada. La relevancia histórica del tema para meso en cuestión, donde la agricultura fue la primera y principal forma de actividad económica y los cambios que se producen en él cambió todo el sistema económico, social y agraria. El documento tiene como objetivo demostrar cómo se produjo la formación y consolidación del programa de modernización de la agricultura, representado por la revolución verde, el noroeste del meso, y el principio de la disipación de modelo a otras regiones del país, analizando el período que abarca las décadas 1960-1970.
\end{abstract}

Palabras clave: Revolución verde. La modernización agrícola. Mesorregión noroeste. 


\section{Notas}

1 O livro Metamorfoses do território: a agricultura de trigo/soja no planalto médio rio-grandense de 19301990, de Aldomar A. Rückert (2003), trata da modernização agrícola na região.

2 O livro Agricultura tropical: quatro décadas de inovações tecnológicas, institucionais e políticas, de Ana Cristina Albuquerque e Aliomar Gabriel da Silva (2008), trata da expansão da agricultura de clima temperado no Brasil, um país tropical.

3 A divisão regional do Brasil em mesorregiões, partindo de determinações mais amplas em nível conjuntural, buscou identificar áreas individualizadas em cada uma das unidades federadas, tomadas como universo de análise, e definiu as mesorregiões com base nas seguintes dimensões: o processo social como determinante, o quadro natural como condicionante e a rede de comunicação e de lugares como elemento da articulação espacial (IBGE, 2012).

4 Ohlweiler (1982, p. 16) estratificou as propriedades rurais, no seu trabalho Sobre o desenvolvimento econômico do Rio Grande do Sul, como: com menos de 10 hectares seriam camponeses pobres, de 10 ha a 50 ha corresponde a camponeses médios, aqueles que conseguem explorar a terra para subsistência, proprietários de 50 ha a 500 ha são a burguesia rural, e acima de 500 ha corresponde ao latifúndio.

5 Segundo Santos (1993, p. 69-88), eram utilizadas várias estratégias para incentivar a migração de pequenos proprietários, sobretudo do noroeste gaúcho. Criaram-se veículos de comunicação com o objetivo de induzir o deslocamento de população. Foi o caso da Rádio Municipal de Tenente Portela, RS, em 1970, e do Jornal da Terra, do mesmo município, em 1971. Nesses, segundo Santos, as mensagens compunham um conjunto de categorias que visavam identificar três temas principais: "A situação social na região de origem; a situação social na região de destino e os meios de realização do trajeto de uma situação de uma à outra região".

\section{Referências}

ALVES, Vicente Eudes Lemos. A mobilidade sulista e a expansão da fronteira agrícola brasileira. Revista Agrária USP [on-line], São Paulo, n. 2, p. 40-68, jun. 2005. Disponível em: <http://www. geografia.fflch.usp.br/revistaagraria/revistas/2/2.htm>. Acesso em: 15 nov. 2012.

ALVES, Clovis Tadeu. A revolução verde na mesorregião noroeste do RS (1930-1970). Porto Alegre: Letra e Vida, 2013.

ALBUQUERQUE, Ana Christina Sagebin; SILVA, Aliomar Gabriel da. Agricultura tropical: quatro décadas de inovações tecnológicas, institucionais e políticas. Brasília: Embrapa, 2008.

ALBUQUERQUE, Rui Henrique P. L. O complexo agroindustrial: uma primeira avaliação técnico-econômica. Revista Ensaios Fee [on-line], Porto Alegre, v. 5, n. 1, p. 121-134, jan. 1984. Disponível em: <http://revistas.fee.tche.br/index.php/ensaios/article/view/349/586>. Acesso em: 15 jul. 2011.

BENETTI, Maria Domingues. Endividamento e crise no cooperativismo empresarial do Rio Grande do Sul: análise do caso Fecotrigo/Centralsul - 1975-83. Revista Ensaios FEE [online]. Jul/Dez 1985, v. 6, n. 2, p. 23-55. Disponível em: <http://revistas.fee.tche.br/index.php/ensaios/ article/view/934/1224>. Acesso em: 15 jul. 2011.

BRUM, Argemiro Jacob. Modernização da agricultura no Planalto Gaúcho. Ijuí: Fidene, 1983.

CONCEIÇÃO, Octavio Augusto C. A expansão da soja no Rio Grande do Sul, 1950-1975. Revista de Teses FEE [on-line], Porto Alegre, n. 6, p. 1-114, out. 1986. Disponível em: <http://cdn.fee.tche. br/teses/digitalizacao/teses_6.pdf>. Acesso em: 15 nov. 2012. 
FAJARDO, Sergio. Complexo agroindustrial, modernizaçao da agricultura e participação das cooperativas agropecuárias no estado do Paraná. Revista Caminhos de Geografia [on-line], Uberlândia, v. 9, n. 27, p. 31-44, set. 2008. Disponível em: <http://www.seer.ufu.br/index.php/caminhosdegeografia/article/view/15725>. Acesso em: 15 jul. 2011.

IBGE. Instituto Brasileiro de Geografia e Estatística: Censo agrícola de 1960 - Rio Grande do Sul. Disponível em: <http://biblioteca.ibge.gov.br/visualizacao/periodicos/44/ca_1960_v2_t13_p2_ rs.pdf>. Acesso em: 15 ago. 2015.

. Censo agropecuário de 1970 - Rio Grande do Sul. Disponível em: <http://biblioteca.ibge. gov.br/visualizacao/periodicos/45/ca_1970_v3_t21_rs.pdf>. Acesso em: 15 ago. 2015.

. IX Recenciamento Geral do Brasil de 1980; Censo agropecuário do Rio Grande do Sul. Disponível em: <http://biblioteca.ibge.gov.br/visualizacao/periodicos/46/ca_1980_v2_t3_n22_p1_ rs.pdf>. Acesso em: 15 ago. 2015.

INSTITUTO BRASILEIRO DE GEOGRAFIA E ESTATÍSTICA. Atlas das mesorregiões. Brasília. Disponível em: <http://200.198.213.88/spr/index.php>. Acesso em: 15 ago. 2012.

. Divisão Regional Brasília. Disponível em: <http://www.ibge.gov.br/home/geociencias/ geografia/default_div_int.shtm>. Acesso em: 15 ago. 2012.

Censo agropecuário, 1960, 1970, 1975 e 1980 .

INSTITUTO BRASILEIRO DE GEOGRAFIA E ESTATÍSTICA. Atlas das mesorregiões. 2012. Disponível em: <http://200.198.213.88/spr/index.php>. Acesso em: 15 ago. 2012.

. Divisão Regional. 2012. Disponível em: <http://www.ibge.gov.br/home/geociencias/geografia/default_div_int.shtm>. Acesso em: 15 ago. 2012.

INSTITUTO DE PESQUISA ECONÔMICA APLICADA. Disponível em: <http://www.ipeadata. gov.br/>. Acesso em: 15 nov. 2011.

KIIHL, R. A.; CALVO, E. S. A soja no Brasil: mais de 100 anos de história, quatro décadas de sucesso. In: ALBUQUERQUE, Ana Christina Sagebin; SILVA, Aliomar Gabriel da. Agricultura tropical: quatro décadas de inovações tecnológicas, institucionais e políticas. Brasília: Embrapa, 2008. p. 189-276.

KIIHL, R. A.; CALVO, E. S. A soja no Brasil: mais de 100 anos de história, quatro décadas de sucesso. In: ALBUQUERQUE, Ana Christina Sagebin; SILVA, Aliomar Gabriel da. Agricultura tropical: quatro décadas de inovações tecnológicas, institucionais e políticas. Brasília: Embrapa, 2008. p. 199 - 218.

LITTLE, Paul E. Etnodesenvolvimento local: autonomia cultural na era do neoliberalismo global. Revista Tellus [on-line], Rio de Janeiro, a. 2, n. 3, p. 33-52, out. 2002. Disponível em: <http:// www.neppi.org/projetos/tellus_detalhes.php?id=346>. Acesso em: 15 abr. 2013.

OHLWEILER, Otto Alcides. Sobre o processo do desenvolvimento econômico do Rio Grande do Sul. Revista Ensaios FEE [on-line], Porto Alegre, v. 3, n. 1, p. 5-40, jan. 1982. Disponível em: <http://revistas.fee.tche.br/index.php/ensaios/article/viewFile/140/449>. Acesso em: 15 nov. 2012.

OLIVEIRA, Péricles F. L. Desenvolvimento agrícola, força de trabalho e imigração rural no Rio Grande do Sul. Revista Ensaios FEE [on-line], Porto Alegre, v. 6, n. 1, p. 145-154, jan. 1985. Disponível em: <http://revistas.fee.tche.br/index.php/ensaios/article/view/923/1210>. Acesso em: 15 nov. 2012. 
RÜCKERT, Aldomar A. Metamorfoses do território: a agricultura de trigo/soja no planalto médio rio-grandense 1930-1990. Porto Alegre: Ufrgs, 2003.

SANTOS, José V. T. dos. Matuchos: Exclusão e Luta: do Sul do Brasil para a Amazônia. Petrópolis: Vozes, 1993. p. 69-88.

SILVA JUNIOR, Luiz Honorato da; NEUMANN, Marguit. Determinantes das médias salariais dos trabalhadores da indústria de máquinas e implementos agrícolas no noroeste do Rio Grande do Sul. Disponível em: <http://www.sober.org.br/palestra/15/101.pdf>. Acesso em: 15 set. 2012.

SITOE, Tomás Adriano. A nova revolução verde africana: de que forma ela pode contribuir para erradicar a fome e a pobreza na África. Revista Desenvolvimento em Questão [on-line], Ijuí, v. 8, n. 15, p. 39-70, jan./jun. 2010. Disponível em: <http://redalyc.uaemex.mx/redalyc/ pdf/752/75216923003.pdf>. Acesso em: 15 set. 2012.

SIQUEIRA, Oscar Graeff. A crise das cooperativas: um estudo comparado entre a cooperativa de Carazinho (RS) e a de Não-Me-Toque (RS). 2001. Dissertação (Mestrado em Desenvolvimento Rural) - Universidade Federal do Rio Grande do Sul, Porto Alegre, 2001. Disponível em: <http:// www.lume.ufrgs.br/bitstream/handle/10183/2194/000315722.pdf?sequence=1>. Acesso em: 15 nov. 2012.

TEDESCO, João Carlos et al. Agroindústrias frigoríficos e cooperativismo. Porto Alegre: EST, 2005.

TATSCH, Ana Lúcia. O arranjo de máquinas e implementos agrícolas do Rio Grande do Sul: infraestrutura produtiva, educacional e institucional. Revista Ensaios Fee [on-line], Porto Alegre, v. 28, número especial, p. 755-774, jan. 2008. Disponível em: <http://revistas.fee.tche.br/index. php/ensaios/article/view/2154/2538>. Acesso em: 15 set. 2011. 